\title{
Working-hour Trends in the Nordic Countries: Convergence or Divergence?'
}

\author{
I Aart-Jan Riekhoff ${ }^{2}$ \\ Senior Researcher, Finnish Centre for Pensions, Finland
}

I Oxana Krutova

Postdoctoral Researcher, Tampere University, Faculty of Social Sciences, Finland

\section{Jouko Nätti}

Professor, Tampere University, Faculty of Social Sciences, Finland

\begin{abstract}
In this article, we investigate changes in usual working hours and part-time work in Denmark, Finland, Norway, and Sweden in recent decades. We analyze whether convergence or divergence occurred between countries, between men and women, and between men and women in each country. We use annual data from the European Labor Force Survey to identify trends between 1996 and 2016 ( $N=730,133)$, while controlling for a set of structural factors. The findings suggest a degree of divergence between countries: usual working hours and the incidence of part-time work were relatively stable in Finland and Sweden, while working hours decreased in Denmark and Norway. The latter is partly driven by a decline among the 15-29 age group. The gender gap in working hours and part-time work was closed somewhat, in particular due to a rise in part-time work among men and a decline among women in Norway and Sweden.
\end{abstract}

\section{KEYWORDS}

EU-LFS / gender / institutions / Nordic countries / part-time work / post-industrialism / working time

\section{Introduction}

ork is moving beyond its traditional borders of time. The standard industrial model (eight-hour day, five-day week, daytime work, free evenings, weekends, annual holidays, and retirement with a pension) is increasingly yielding to a new 'postindustrial working-time regime' (O'Carroll 2015). Under the pressures of technological change and globalization, this new regime is characterized by labor market deregulation, a de-standardization of both duration and timing in working time, increasing work intensity, and a blurring of the boundaries between family and working life (Anttila et al. 2015). At best, the new regime may bring more flexibility and autonomy for a majority of employees and contribute to a more productive economy. At worst, it creates new risks for individuals and their families and reinforces societal inequalities (Warren 2015a).

While the trend toward a postindustrial working-time regime might be present in most industrialized countries, its intensity and outcomes are not necessarily the same

\footnotetext{
${ }^{1}$ You can find this text and its DOI at https://tidsskrift.dk/njwls/index.

${ }^{2}$ Corresponding author: Aart-Jan Riekhoff. E-mail: arie.riekhoff@etk.fi.
} 
everywhere. Countries have various regulatory traditions for working conditions, and institutional change is likely to be path dependent. The Nordic countries have a tradition of strong and inclusive labor market regulation concerning collective bargaining, working conditions, worker autonomy, and combining work with family life (Anttila et al. 2015; Gallie 2007). Therefore, the Nordic countries constitute an interesting case to observe changes in working hours in the last two decades. Studies have shown that overall working hours in these countries have been relatively stable (Eurofound 2016, 2017). Yet, little is known about the mechanisms behind possible changes and whether stability or decline can be found among all groups in society. There are economic, demographic, and institutional differences between the Nordic countries and variation in their reform trajectories, which may contribute to different developments in their working-time practices. Comparing four Nordic countries (Denmark, Finland, Norway, and Sweden) can strengthen our understanding of how labor markets in seemingly similar countries converge or diverge under similar pressures.

One distinguishing feature of the Nordic employment and working-time regime has been high levels of female labor market participation and full-time employment. In recent decades, changes in policies and practice have taken place that could lead to further convergence in working hours between men and women. Yet, there might also be differences in the pace at which convergence between men and women is taking place in each country. In Denmark, Norway, and Sweden, for example, part-time work increased considerably among men, while remaining stable among women (Furåker 2013). In Finland, part-time work continues to be relatively uncommon. Sweden and Norway expanded options for paternity leaves more than Denmark and Finland (Björnberg 2016), possibly leading to fathers reducing their working time more in the former than in the latter countries.

In the remainder of this article, we examine trends in working time in Denmark, Finland, Norway, and Sweden over two decades. We use two indicators for working time. First, we employ usual working hours to analyze general trends in working time. Second, we also investigate trends in part-time work (i.e., 1-34 working hours per week). Usual working hours is an average and it does not yield detailed information of particular working-time arrangements. Part-time work, on one hand, is a form of nonstandard employment and can be an indicator of greater precariousness and financial hardship among workers (Rasmussen et al. 2019; Warren 2015b). On the other hand, part-time work is an important mechanism for balancing work and family life, especially for women and increasingly also for men. If working hours have converged between men and women, can this be explained by a rise in part-time work among men, a decline among women, or both?

Our analysis focuses on country and gender differences and trends over time. We address three questions: whether there is convergence or divergence in working time between the Nordic countries, whether there is convergence or divergence in working time between men and women, and whether there are differences between countries in the working-hour trends of men and women. In each research question, we examine the effects of time, gender, structural factors, and the interactions between these on usual working hours. We analyze to what extent structural changes in workforce demographics (age, marital status, nationality, and education) and sector of employment explain differences in usual working hours in each country, for each gender, and for each gender in each country.

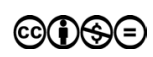




\section{Convergence and divergence in working time in the Nordic countries}

There are contending theories about whether working conditions across countries are converging, diverging, or remaining stable. On one hand, the pressures of globalization and technological change have rendered countries and country regimes more similar and that working conditions, including working hours, have converged because of the need to compete in a global and postindustrial economy (Gallie 2007). Convergence can be upward, as technology and automation take over low-skilled jobs, while there are more high-skilled jobs with better working conditions, leading to fewer and more flexible working hours for a larger part of the working population. Convergence can also be downward, if these pressures instead induce a degradation of labor and worsening working conditions because of an international 'race to the bottom' (Braverman 1974). Downward pressures do not necessarily affect the working conditions of the whole population alike. Recent literature has emphasized trends of dualization and polarization in the labor market, where high-skilled workers enjoy good working conditions, while the low-skilled become increasingly marginalized (Goos \& Manning 2007; Kalleberg 2011).

Institutionalist theories, on the other hand, predict relative stability and persistent divergence between countries. Outcomes of globalization and technological change differ by country or country regime. Various production or employment regimes render their stability from vested interests of the state, employers/firms, and employees, and their continuous strategic interactions, thereby creating a set of norms and cultural practices that frame mutual expectations between the parties involved (Hall \& Soskice 2001; Gallie 2007). In most regime theories, the Nordic countries are grouped together within one regime type. In terms of working-time arrangements, distinct 'Nordic regimes' have been identified in the literature along at least three relevant dimensions: working time regulation through bargaining at a macro-level, working-time flexibility at the workplace, and gender equity in working-time arrangements.

First, at a macro-level, the Nordic countries are characterized by a 'negotiated' working-time-setting regime (Berg et al. 2014; Eurofound 2016). Collective bargaining agreements between employer and employee organizations, predominantly at the sectoral level, are the key instrument in establishing working-time standards. This working time configuration is the result of a tradition of high trade union density and broad coverage of collective bargaining (Gallie 2007). The Nordic states stand in contrast with countries in the 'mandated' regime, where regulating working time is the primary responsibility of the state, and the 'unilateral' regime, where there is only a minor role for statutory legislation, and employers determine working time through individual work contracts. According to Eurofound (2016), countries belonging to the 'negotiated' working-time setting regime had the lowest regulated working hours and actual usual hours worked, particularly due to the strong voice of employee organizations.

Second, working-time regimes are not merely the result of formal agreements and legal norms at a macro-level but also of voluntary and customary practices that influence working-time practice at a micro-level (Rubery et al. 1998). Tijdens and Chung (2013) found the Nordic countries among a cluster of countries with high employeeand employer-centered flexibility and in contrast to country clusters with low overall 
working-time flexibility or only employer-centered flexibility. This means that flexibility in working time can benefit both employees through arrangements such as training, parental, and care leave, as well as employers, for example, through overtime, unusual hours, and shift work. Hybrid arrangements can benefit both sides and include phased retirement, part-time work, and flexible or reduced working hours. In another study, Anttila et al. (2015) identified the Nordic countries as part of a distinct working-time regime, which distinguishes itself by low incidence of unsocial working hours, fewer working hours, high working autonomy, above-average work-time intensity, and high workplace flexibility.

Third, the Nordic working-time regime is characterized by relative strong gender equity in working-time arrangements. Various studies emphasized the gender dimension to working-time regimes (Figart \& Mutari 2000; Rubery et al. 1998). In the 'market', or 'liberal flexibilization' regime, men are more likely to work full time and overtime across the lifetime, regardless of marital status, whereas women tend to work part time once children are born (Figart \& Mutari 2000). In the 'dualistic', or 'male breadwinner' regime, the household division of labor is by gender; women often leave paid work completely after childbirth, while men work full time with little flexibility in hours. In the 'inclusive', or 'solidaristic gender equity' regime, which includes the Nordic countries, full-time work with little flexibility is the norm for both men and women.

Based on the institutional and regime theories, we expect both relative similarity between the Nordic countries in working-time arrangements and relative stability over time. Collectively agreed weekly working hours remained relatively stable for the past decades. In Denmark, they were set at 37 in 1990, in Finland 37.5 in 1995, and in Norway 37.5 in 1987. Only Sweden experienced a decrease, from 38 in 1999 to 37.1 in 2014, while variation by sector has been greater due to separate sectoral agreements. Stability in agreed working hours has led relative stability in actual hours worked as well. Eurofound (2016) discovered a slight increase of annual working hours between 2004 and 2014 in Denmark and Finland, whereas Norway showed a slight decrease. Only in Sweden was the increase in working hours considerable during the same period. In Finland, part-time work is less common among both men and women compared with the other three Nordic countries in this study (Furåker 2013).

It should be noted that regimes rarely constitute uniform blocks and that considerable variations in particular institutions within regime types may exist. Several studies showed that while struggling with similar pressures, the Nordic countries continued to constitute a single model distinct from other European countries in a broad variety of aspects (Berglund 2014; Kvist et al. 2012; Mustosmäki 2017). Yet, it is also possible to emphasize differences and diverging trends in the Nordic region with regard to particular aspects, such as collective bargaining (Andersen et al. 2014; Gooderham et al. 2014), temporary employment and job insecurity (Berglund 2014; Rasmussen et al. 2019), and family policies (Björnberg 2016).

There are several reasons why the emergence of a postindustrial working-time regime has led to divergence in working hour trends among the Nordic countries. First, the timing and pace of deindustrialization may differ between countries. Shifts toward a more services-oriented economy occurred earlier in Denmark, Norway, and Sweden, whereas in Finland, the onset of deindustrialization was relatively late. Second, as described by theories of labor market dualization, a post-industrial working-time regime can have varying effects on specific groups in society. Among highly educated 
employees in dynamic sectors deindustrialization may lead to a lengthening and intensification of working time, and a marginalization of private life and concentration on work (Hochschild 1997), while the less educated are more affected by low-autonomy and shorter work hours (Chatzitheochari \& Arber 2012; Warren 2015a). Third, policy reforms in various policy domains, such as labor-market, family, education, retirement, and migration policies, may intensify the effects of deindustrialization toward specific groups, but not toward others. Therefore, it is important to not only look at convergence and divergence at a country level, but also analyze the changes in working hours by age, education, marital status, and country of birth.

\section{Convergence and divergence in working time between men and women}

The Nordic 'inclusive' and 'solidaristic' model is usually showcased as the most gender neutral in terms of employment rates and working conditions. Female employment rates are among the highest in Europe. A broad set of labor market and family policies, such as parental and care leaves and public provision of children's daycare, offer possibilities for women to stay active in the labor market throughout the life course. While during the parenting life phase women tend to decrease working hours and men tend to increase time spent at work, a study by Eurofound (2017) indicated that this gender gap is smaller in the Nordic countries than in Continental and Anglo-Saxon European countries. Yet, as elsewhere, there have been stark gender differences in working-time patterns as well. Women are more likely than men to work part time (Eurofound 2016, 2017; OECD 2018). This is related to women being predominantly employed in service jobs and especially in the public sector (Estevez-Abes 2006), where working hours are shorter than in agriculture and manufacturing jobs and in the private sector. In particular after childbirth, women are more likely to return to work only part time, whereas men continue working fulltime.

In spite of this continuous working hour gap between men and women, convergence between men and women's working hours can be expected for several reasons. Although traditionally already high, labor market attachment of women has continued to increase during the past two decades, possibly contributing to more hours at work. Increases can be found especially among women in their parenting-age (in particular in Norway and Sweden) and in the age bracket of 55-64 (in particular Denmark and Finland) (OECD 2018). Educational attainment among consecutive cohorts of women has continued to rise, while research has shown that there is a positive relation between level of education and hours worked (Fagan et al. 2012). Moreover, Nordic labor markets are increasingly desegregating, with women being employed in a greater variety of positions and occupations (Ellingsæter 2013).

Men have in recent years increased their participation part-time work (Furåker 2013) and decreased their usually worked hours in full-time jobs in all Nordic countries (Eurofound 2016). As women have traditionally been employed primarily in the services sector, a continuing trend of deindustrialization has potentially reduced men's working hours more than women's. Finally, in all four countries, fatherhood policies have been expanded, leading to men's longer absences from work during the parenting phase and therefore reduced time spent at work (Haataja 2009). 
Yet, the extent to which men and women's working hours are converging might differ in each of the countries due to various reasons. First, countries may experience differences in economic and demographic trends. Deindustrialization and rises in women's educational attainment may occur at different speeds in different countries, leading differences in the pace at which men and women's working hours change. Denmark has been a frontrunner in deindustrialization and women's education, while Finland has been a relative latecomer in both aspects. This may lead to different levels of convergence between men and women's working time in both countries. Second, policies and reform trajectories in each of the countries can result in divergence. Reforms in Sweden and Norway have been more supportive of paternity leaves than in Denmark and Finland (Björnberg 2016; Haataja 2009), potentially leading to differences in the closing of the gender gap in working hours. Third, country-specific norms and values about gender and working time play a role in determining especially how much a woman is expected to work (Mósesdóttir \& Ellingsæter 2017). Policy or economic trends cannot fully explain why, for example, part-time employment has increased among men in Denmark, Sweden, and Norway but not in Finland or why taking paternity leave is more popular among fathers in Sweden than in Finland.

\section{Data, measures, and methods}

\section{Sample and participants}

For our analysis, we relied on the European Union Labor Force Survey microdata (EULFS) for 1996-2016. The EU-LFS is conducted in the 28 EU member state countries and two candidate countries and three European Free Trade Association countries (Norway, Switzerland, and Iceland). It is a large household sample survey conducted on a quarterly basis for people aged 15 years and older both in and outside the labor force. We used annual data for Denmark, Finland, Norway, and Sweden. Iceland was omitted from the analysis because the number of employed respondents was relatively small, especially during the years 1996-2004, and level of education, one of the key independent variables, was missing for the years 1996-1998.

Because the original numbers of respondents vary considerably between the Nordic countries and years, and to obtain more balanced data, we selected similar samples from each country and for each year (Denmark $N=204,950$; Finland $N=205,151$; Norway $\mathrm{N}=204,621$; and Sweden $\mathrm{N}=204,406$ ). This was done by drawing random samples while weighting the data according to the population's composition. These samples were used in the descriptive analysis $(\mathrm{N}=819,128)$. In the regression models, the number of respondents is lower $(\mathrm{N}=730,133)$ because of missing cases in the explanatory variables. The analysis limits itself to employees aged 15-64 years who were in a paid employment relation at the time of the survey. One potential risk in this selection is that it includes anyone in paid employment, including those whose main activity is something else, for example, being a student. EU-LFS contains a variable on self-reported main status, but this variable was missing for Norway and Sweden for multiple years and therefore could not be used. We will come back to this limitation in the results and discussion sections.

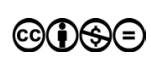




\section{Measures}

\section{Dependent variables}

We employed two types of dependent variables: average usual hours worked and working short hours. In the EU-LFS, respondents supply the number of hours per week usually worked in the main job (1-80 hours). 'Usual hours worked' are defined as the modal value of the actual hours worked per week over a long reference period, excluding weeks when an absence from work occurs (e.g., holidays and leaves). The reference period is at least the last four weeks and at most the last three months, without counting any absence from work (1-3 months). For employees covered by an employment contract, usual hours include contractual work hours, and mandated overtime. A binary variable for part-time work was created by distinguishing between those who work 35 hours or more and those who work less than 35 hours, but at least one hour a week. We did not analyze changes in the incidence of working long hours, that is, more than 40 hours per week. We found that the incidence of long hours was very low in all countries and did not change considerably over time. Moreover, we observe an overall decline in working time, not an increase. Even periodical increases in working hours, such as among Swedish and Norwegian women, held no relation to increases in long working hours.

\section{Explanatory variables}

In the analysis, we control for structural factors that might explain differences in working hours and working-time trends. Dummies were included for age groups (15-29, 30-44, 45-54, and 55-64) to analyze the effects of the population's age structure at each point in time. We expect relatively low working hours among the youngest age group, lower hours among women but higher among men during the parenting phase of the life course (30-44), an evening-out during ages 45-54, and a reduction in hours in anticipation of retirement during the final stage of the work career. A dummy variable for being married is used as a proxy for the possibility that family formation affects working hours. Information on cohabitation or having children is, unfortunately, not available in EU-LFS annual data. Dummies were included for having a tertiary degree to control for the effects of education. We control for being an immigrant with a dummy for being born outside the country of residence. Immigrants often have poorer work conditions than natives, including a higher risk of working long hours (Sterud et al. 2018). To analyze the effect of economic sector of employment, a dummy is based on the economic activity classification (NACE) and contains two categories: manufacturing (including agriculture and construction) and services.

\section{Methods}

Trends in usual working hours were analyzed separately by country, gender, and countrygender interactions. First, Figures 1-6 present an overall picture of the development of usual working hours and part-time work without controls. In this descriptive analysis, we employed separate and combined classifications of country and gender. The 
figures are based on mean comparisons and cross-tabulations and presented to visualize where and what kind of changes happened over time. In a next step, we tested temporal changes in usual working hours and part-time work between countries and genders with cross-product terms in a linear regression model with controls (age, level of education, marital status, nationality, and economic sector). As the models for short hours employ a binary dependent variable (0-1), these are in fact linear probability models. Coefficients in linear probability models can be interpreted as the effect of the independent variable having a certain value on the dependent variable having the value 1 . In contrast to logistic regression, coefficients can be compared between different models (Mood 2010).

As the hypothesized developments of country and gender differences in working time and part-time work take-up reflect a simple strengthening or weakening of these differences, we used survey year as a linear period effect in regression models, making the results easily interpretable (Mustosmäki et al. 2017). Significant period effects indicate, depending on the intercept (initial status in 1996), either strengthening or weakening of differences between countries or genders. However, linear trends do overlook information on periodical variation, such as from changes in the economic situation. As we address only general trends of increasing or decreasing differentiation, the simplification of these more nuanced periodical changes is necessary.

\section{Results}

\section{Structural changes}

Table 1 describes the changes in structural factors for employees between 1996-1998 and 2014-2016. Among the most notable changes is, first of all, the steep rise in education level, especially for women. The increase in education levels was greater in Norway and Finland than in Denmark and Sweden, leading to a certain degree of divergence. The working population aged in all four countries and average ages converged between Finland, Norway, and Sweden. The working population in Denmark remained relatively young. The proportion of marriages declined considerably, except in Denmark, and converged somewhat between countries. Confirming our expectations, the proportion of non-nationals increased, but at a much higher rate in Norway and Sweden, leading to diverging trends with Denmark and Finland. Service sector employment expanded, in particular for men. Norway experienced the lowest growth in service sector jobs, Sweden the highest.

\section{Changes in usual working hours}

Figure 1 shows the 1996-2016 changes in average usual working hours for each country. Employees in Finland and Sweden worked longer hours than those in Denmark and Norway. Average working hours were relatively stable in Finland and Sweden, with a slight upward trend in the latter. Usual working hours declined in Norway and especially in Denmark. In Norway, this decline was primarily due to a drop in working hours between 2002 and 2003. Denmark experienced a longer downward trend, starting in 2006. Overall, working-hour trends diverged between the four Nordic countries. 


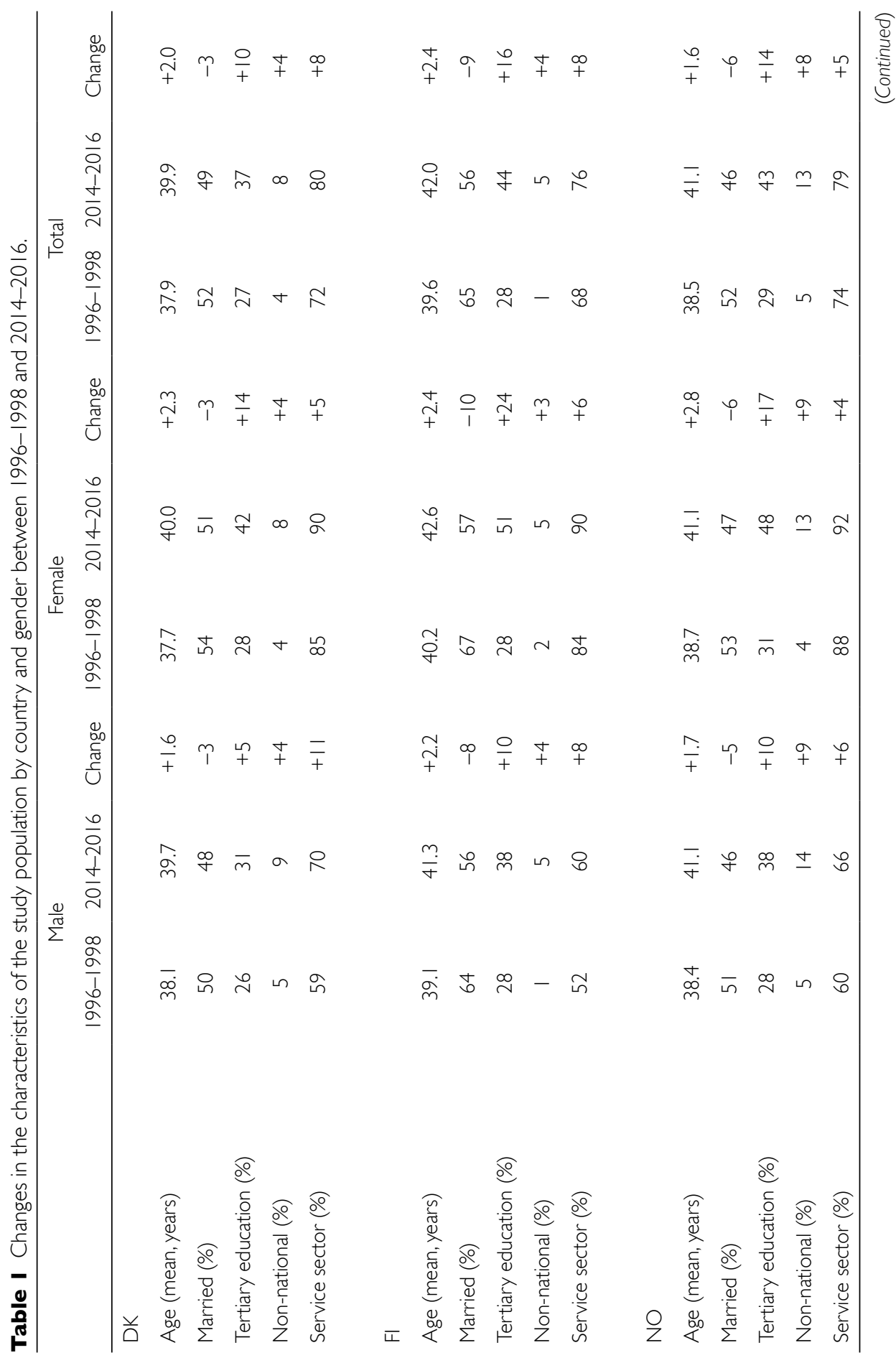




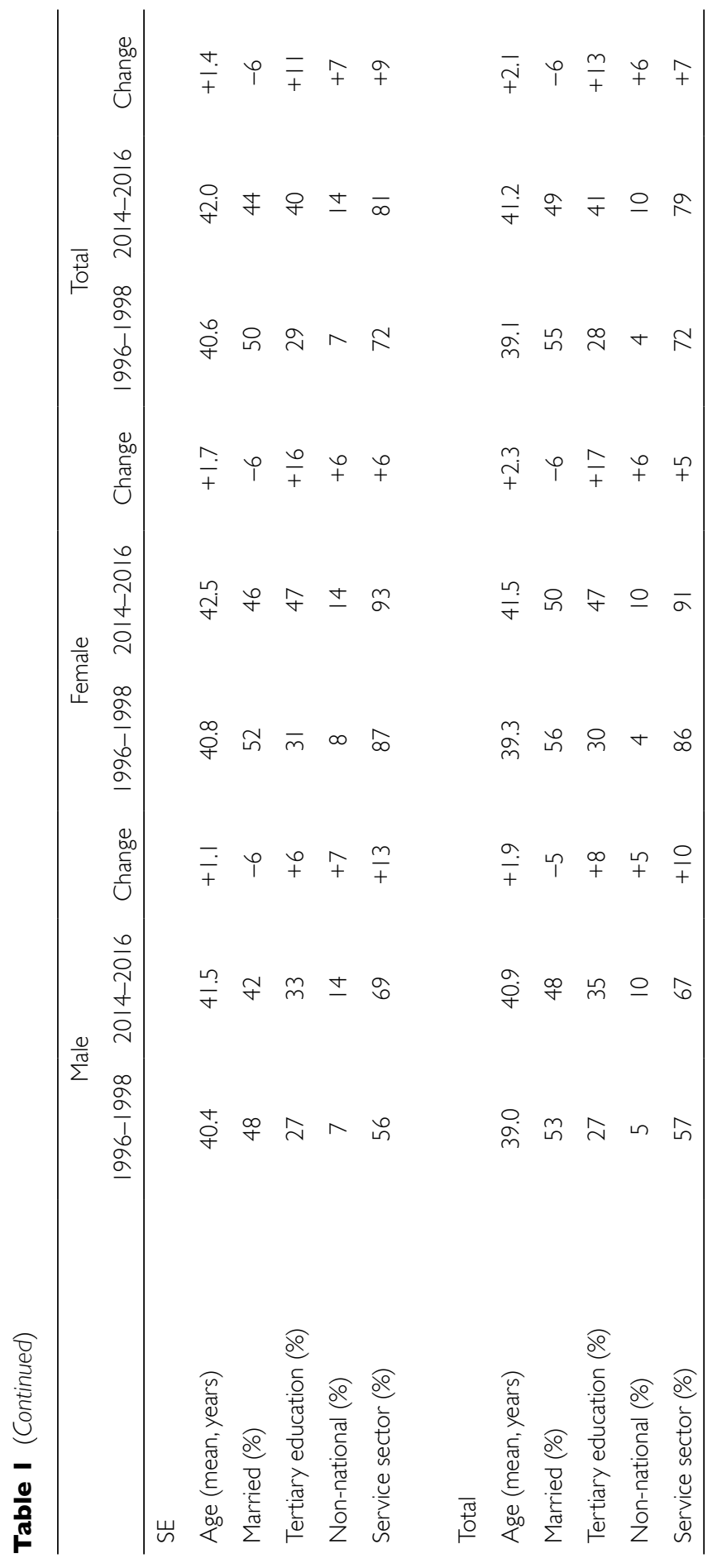


In 1996, the differences between countries were smaller than in 2016. In 1996, Finns worked on average 36.9 hours, Swedes 35.5, Norwegians 35.0, and Danes 34.4. By 2016, this changed to 36.8 hours for Finns, 36.2 for Swedes, 33.9 for Norwegians, and 31.8 for Danes. Figure 2 shows the results by gender. Compared with men, women had substantially shorter usual working hours. There was a degree of convergence, especially due to a decline for men, from 37.8 hours in 1996 to 36.3 in 2016, while women's hours were mostly stable around 33.

Figure I: Average usual working hours by country, 1996-2016.

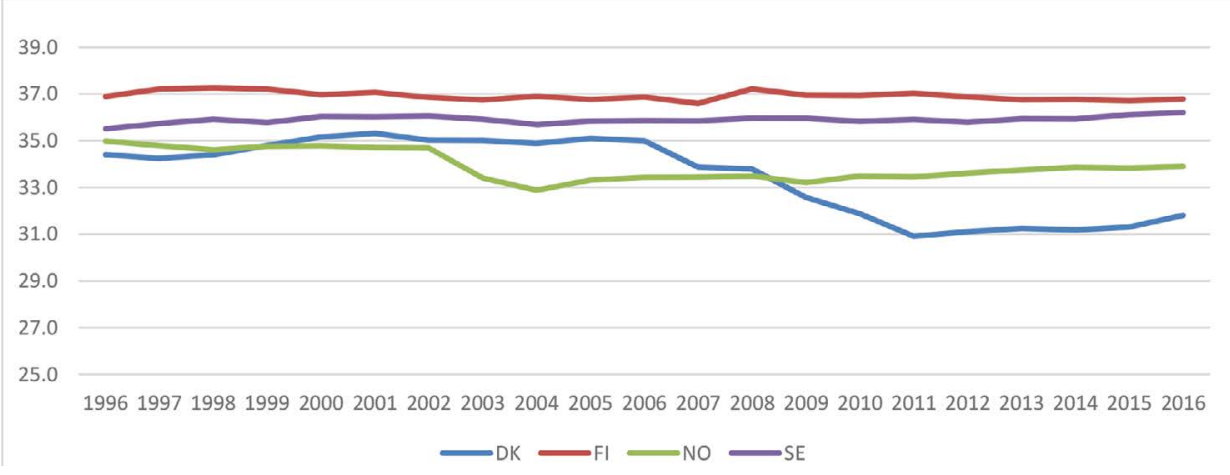

Figure 2: Average usual working hours by gender, 1996-2016.

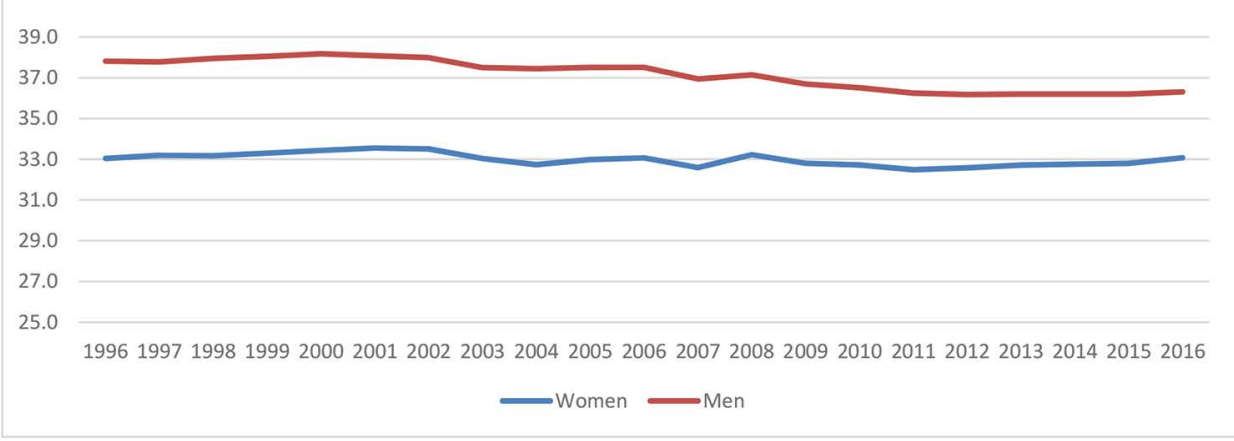

Figure 3 presents how the gender gap in working hours developed in each of the countries. In Denmark, usual working hours declined more for men than women, closing the gender gap slightly. In Finland, usual hours remained stable for both men and women, not substantially changing the gender gap. In Norway, the gender gap was seemingly the largest for all countries. However, men's working hours decreased, while women's hours have been slightly increasing since 2004, leading to a decline in gender differences. In Sweden, the convergence of usual working hours between men and women was most visible. The hours of men declined, while those of women steadily increased.

Table 2 presents the results of the regression analysis of usual working hours per country and by gender with controls for structural factors. The intercepts indicate the estimated 
Figure 3: Average usual working hours by country and gender, 1996-20I6.
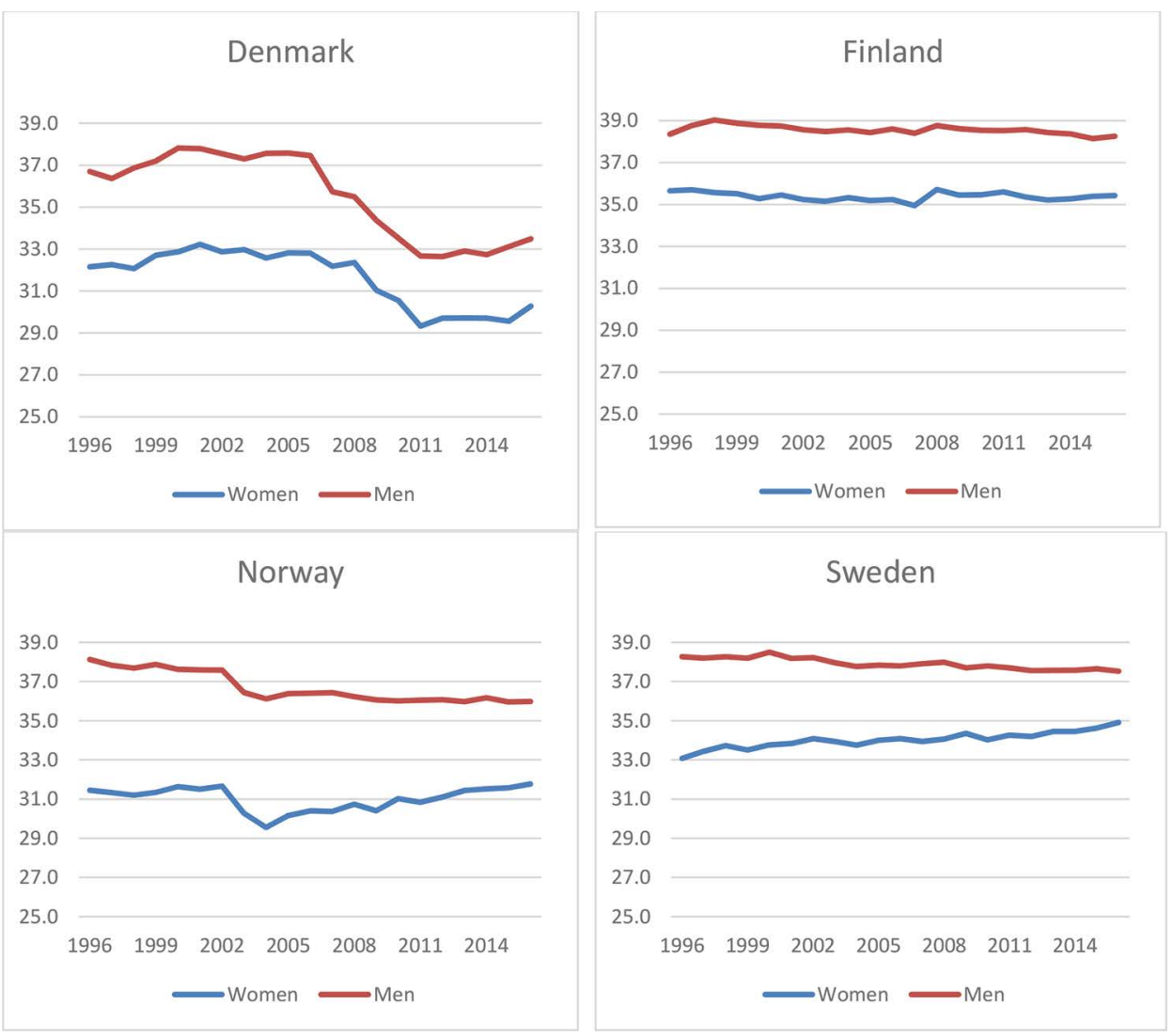

working hours at $\mathrm{t}=0$ (i.e., 1996) for the reference group aged 55-64 years, nonmarried, low or middle educated, and native citizens employed in manufacturing. They confirm that women worked fewer hours than men in all four countries. The Year covariate estimates the trend in working hours over time. This time trend is negative for all subgroups, except for women in Sweden where there is an upward yet small effect, confirming the convergent effect between men and women that was also visible in Figure 3. A downward trend is most considerable for Danish men $(b=-0.26)$ and women $(b=-0.19)$, followed by Norwegian men $(b=-0.10)$. Overall, the results indicate a downward convergence between men and women within countries, as working hours are shown to decrease at a faster rate for men than for women in Denmark and Norway and hours increased among women in Sweden. Finland marks an exception. Between countries, the results confirm the picture of downward divergence, with Denmark and Norway reducing working hours at a faster rate compared to the relatively stable developments in Finland and Sweden.

The controls in Table 2 show substantial differences between countries and genders in the associations between structural factors and working hours. In all countries, the youngest age group worked the fewest hours, but in Denmark (men's $b=-7.49$ and women's $b=-8.24)$, this effect was the largest. In Finland, this effect was much larger for 


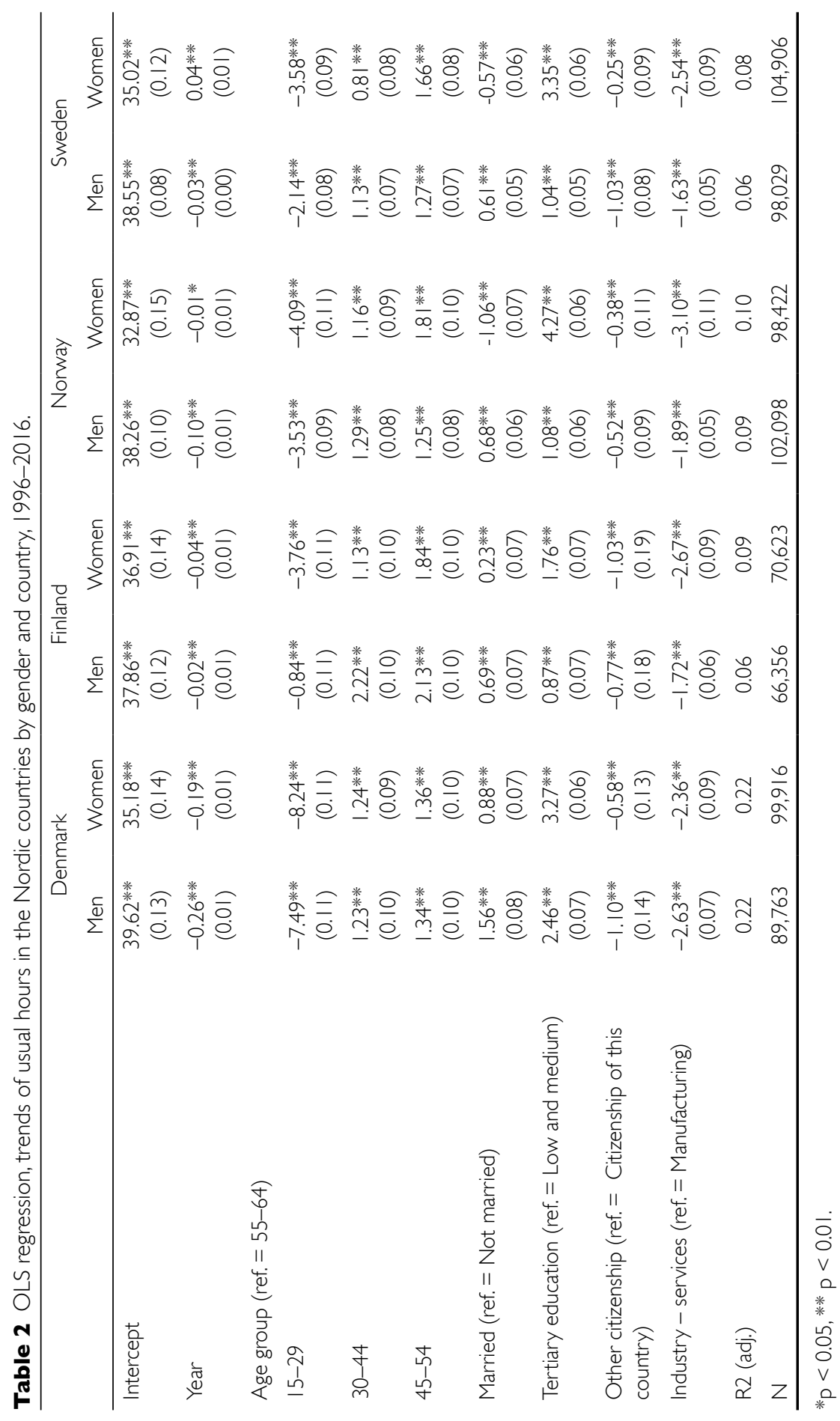


women $(b=-3.76)$ than men $(b=-0.84)$. Those who were married were more likely to work longer hours, apart from Norwegian and Swedish women. Higher education had a stronger positive effect on women's working hours than men's, especially in Norway (higher-educated men worked 1.08 hours more but higher-educated women 4.27 hours more) and Sweden (men 1.04 hours and women 3.35 hours more). Unlike expected, immigrants worked fewer hours in all countries. Usual working hours were lower in the services sector in all countries and working in the services sector had a stronger negative effect on women's than on men's working time, except in Denmark.

Table A1 in the Appendix shows the results of the models with interactions between the structural factors and the Year variable included. The interactions allow us to check the effects of the structural factors on the changes across years, while making the trend lines specific for each group. The results show that in all countries, especially the gap in working hours between oldest and youngest age groups increased across time. This effect was especially strong in Denmark and present to some extent in Norway. Table A1 further shows that for most of the other structural factors, the effects on working time trends are smaller and more mixed between genders and countries. Married women increased their working hours compared to unmarried women in Denmark, Norway, and Sweden, which may be an indication of a more balanced division of roles between men and women in the household that allow women to work more hours. However, only in Denmark did married men also reduce their working time compared with unmarried men. The gap in working hours increased between higher- and lower-educated in all countries, except for Sweden. Employment sector also had varying effects. Among men, working hours declined in the service sector more than in manufacturing in all four countries. For women in Denmark, the difference in usual hours worked between sectors decreased, while in the other countries, there was no considerable change in the working hour gap between sectors among women.

As mentioned in the Methods section, it was not possible to check respondents' main status across all years and it is possible that the overall reduction in hours among the whole sample is driven by the youngest age group due to a particular increase of students with part-time jobs in the survey. Therefore, as a robustness check, we ran the same analysis as in Table 2, but excluding the age group 15-29. These results (not reported) indicated only small differences in the time trends for Finland and Sweden from the ones reported in Table 2, although the coefficient for women in Finland became insignificant. In the cases of Denmark and Norway, however, the robustness check showed weaker negative time trend coefficients for men $(b=-0.11$ for Denmark and $b=-0.05$ for Norway). Among Danish and Norwegian women these coefficients turned positive $(b=0.02$ and $b=0.09$, respectively) and were statistically significant. Hence, by excluding the youngest age group, strong convergence in working time between genders can be found in all Nordic countries. Moreover, the divergent effect that was found between countries due to decreases in work hours in Denmark and Norway partly disappears.

\section{Changes in the incidence of short working hours}

Figure 4 indicates that the share of employees working fewer than 35 hours per week has remained relatively stable in Finland, Sweden, and Norway, although in the latter country there was greater fluctuation over time. In Denmark, there was an increase in part-time 
work between 2007 and 2011, after which the trend stabilized again. As expected, Finland had the lowest incidence of part-time work of around $15 \%$ of the employees. In Sweden and Norway, this share was around $25 \%$. The percentage of those working short hours increased in Denmark from around 25 to 35 in the late 2000s. Mainly as a result of the increase in part-time work in Denmark, there was some divergence between countries. Figure 5 shows that around $35 \%$ of the Nordic women worked short hours and that this percentage was relatively stable between 1996 and 2016. The share of men in part-time work slowly but steadily increased from $10 \%$ in 1996 to $15 \%$ in 2016 . Due to the increase of short hours among men, convergence between genders can be observed.

Figure 4: Short usual working hours ( I-34 per week) by country, 1996-2016.

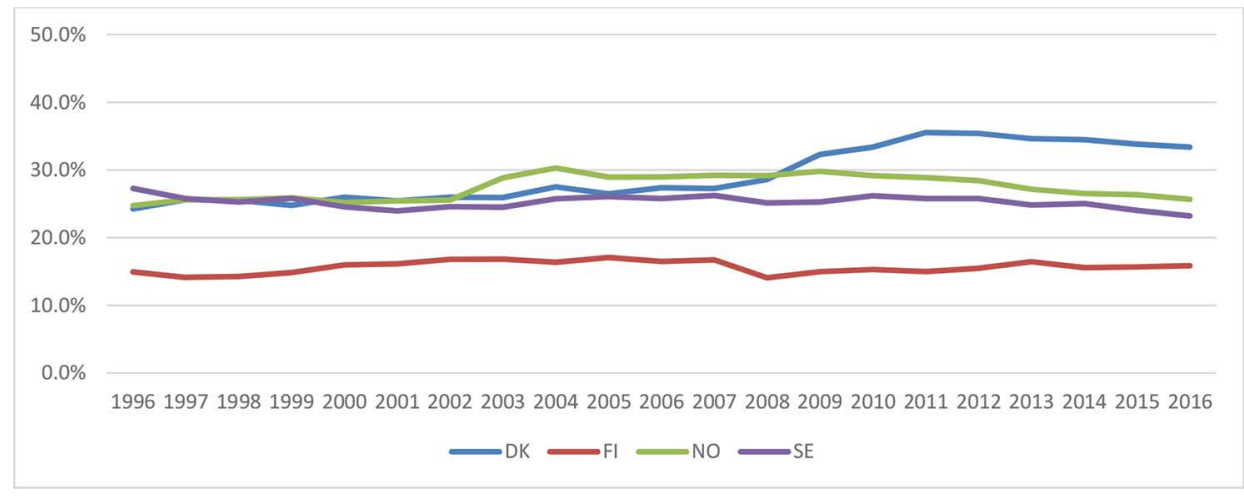

Figure 5: Short usual working hours (I-34 per week) by gender, 1996-20 I6.

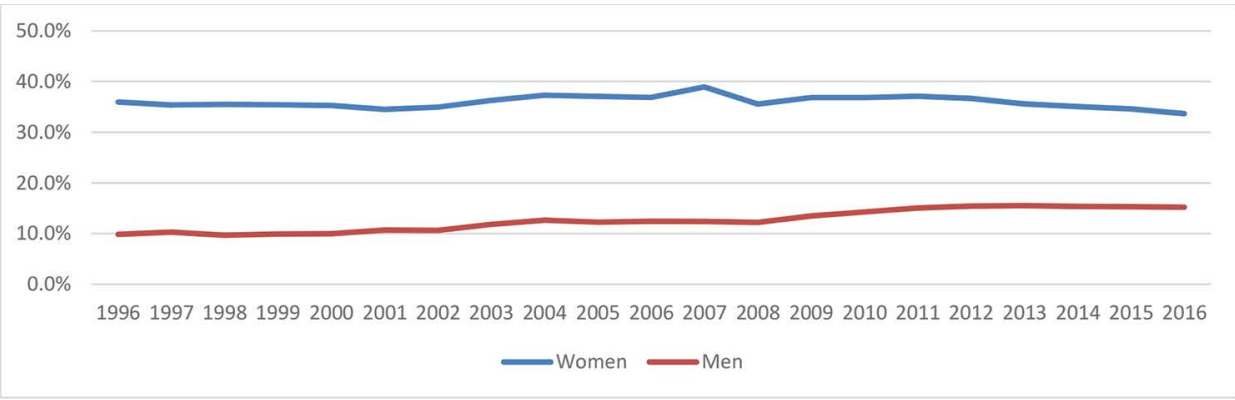

The changes in the gender gap in part-time work are presented in Figure 6. In Denmark, the gap was reduced somewhat due to a larger increase in short hours among men than among women. In Finland, no substantial changes in the gender gap could be observed. The gap between men and women decreased in Norway and Sweden due to both a decline in short hours among women (in Norway after 2004 in particular) and increases among men. In these two countries, convergence between genders was most visible.

Table 3 presents the results of the linear probability models for working short hours per country and by gender with controls for structural factors. The intercepts indicate the estimated percentage of respondents working short hours at $t=0$ (i.e., 1996) for 
Figure 6: Short usual working hours ( I-34 per week) by country and gender, 1996-20 I6.
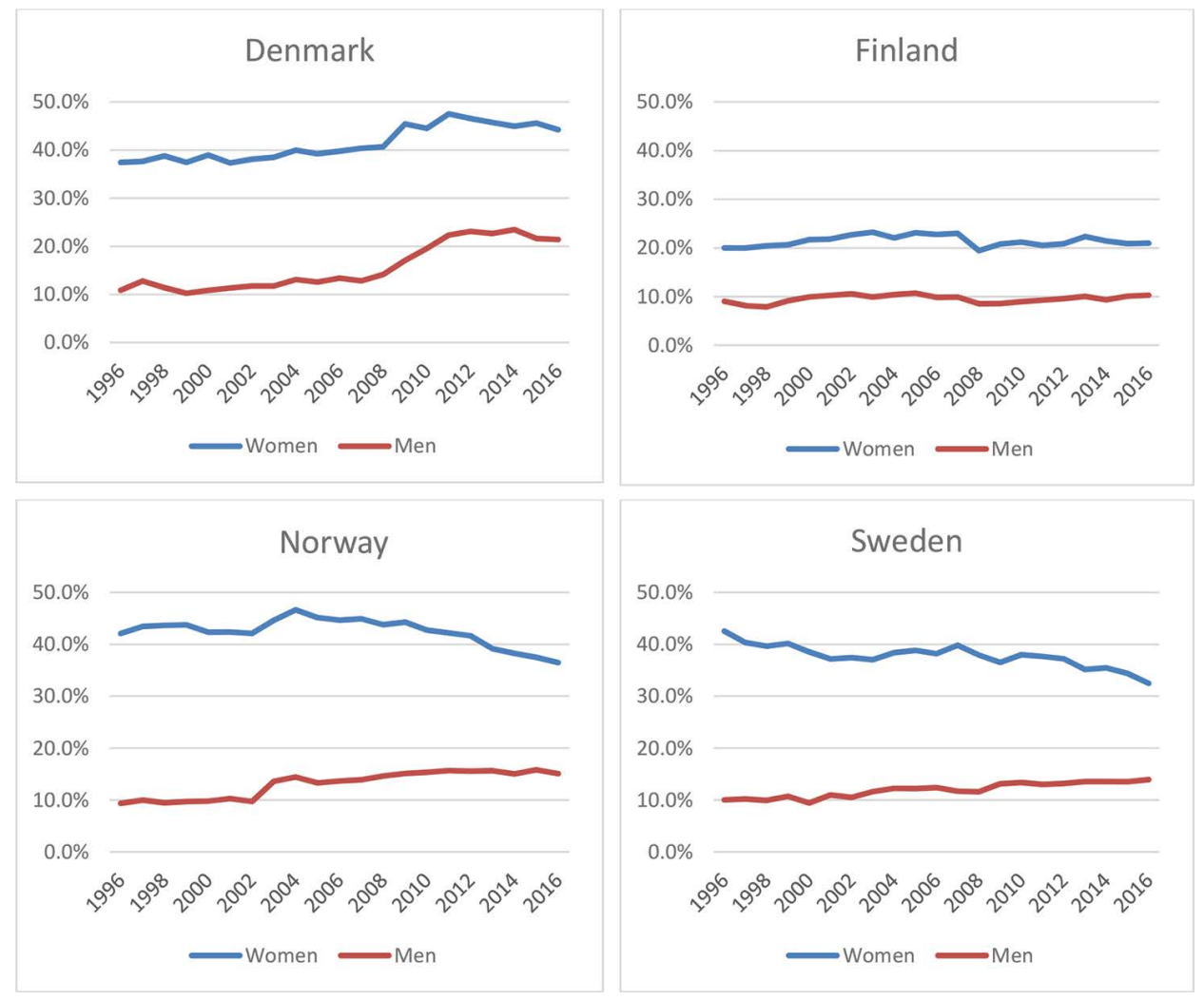

the reference group aged 55-64, married, low or middle educated, and native citizens employed in manufacturing. The coefficients for the Year variable indicate the estimated year-on-year change in this percentage. The results show significant increases in short hours among Danish, Norwegian, and Swedish men as well as Danish and Finnish women. Part-time work decreased significantly among Norwegian and Swedish women. These results confirm the findings from Figure 4 that the divergence between countries was mainly due to the rather considerable increase in short hours in Denmark. In line with Figure 6, the gender gap most obviously closed in Norway and Sweden, while results for Denmark and Finland are more ambiguous. However, when once again excluding the youngest age group from the analysis (not reported), we found that the coefficient for the time trend is close to zero for men and becomes negative for women $(b=-0.01)$ in the case of Denmark. The negative coefficient for Norwegian women becomes larger $(b=-0.04)$. No substantial changes in the results occur for Finland and Sweden.

The results for the structural factor covariates are much in line with the findings for usual working hours in Table 2. Shorter hours are most common among the age group of 15-29. Interestingly, in all countries, married men are less likely to work shorter hours, whereas women are more likely to do so (although this finding was not statistically significant for Finnish women). This finding supports our expectation that during 


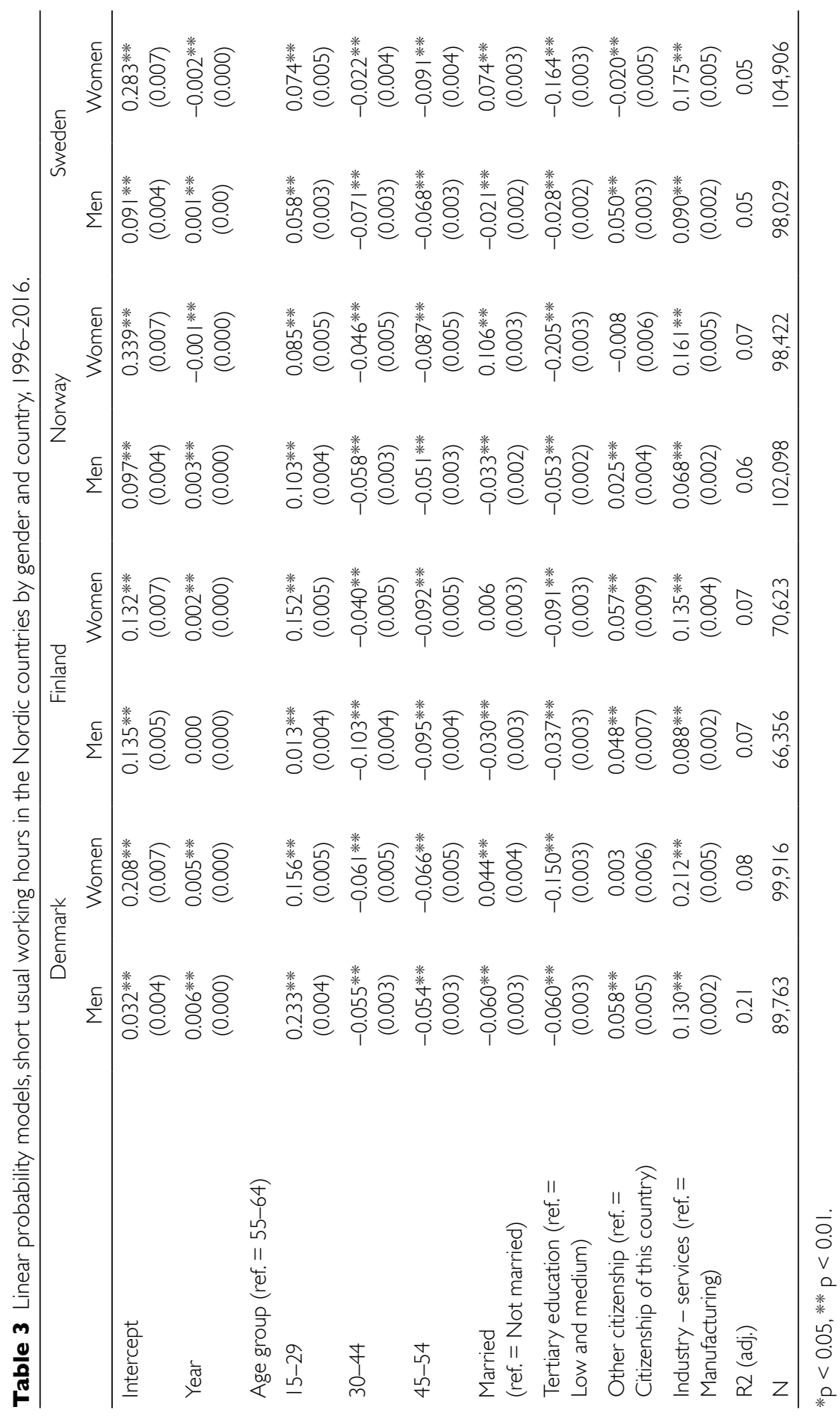


the family formation phase, men continue to work more hours, whereas women tend to reduce their working time. Also as expected, employees with higher education were less likely to work short hours, while this effect was greater for women than for men. Parttime work was more common in the services sector in all countries. Again, this effect was greater for women than for men.

In Table A2 in the Appendix, the interaction effects of the Year variable with the structural factors were included in the models. In Denmark, similar to the drastic decrease in usual working hours, there was a rising gap between the likelihood of the 15-29 and the other age groups to be in part-time work. Also in the other countries, the risk gap of short hours between these age groups increased between 1996 and 2016. Married women became less likely to work short hours compared with unmarried women in Denmark, Norway, and Sweden. Yet, Finnish married women's participation in parttime work increased somewhat relative to unmarried women. This might be explained by a 'catching-up effect', as part-time work has been relatively uncommon in Finland. There is no evidence that married men have started to do more part-time work in any of the countries. The education gap in part-time work increased for men and women in Denmark and Norway and among Swedish men. Among Swedish women, the large education gap was somewhat reduced. For men in the services sector, the participation in part-time work increased compared to men in manufacturing in all countries. Norwegian women employed in the services sector also increased part-time work in relation to those in manufacturing, whereas among Danish and Finnish women, this gap decreased. The increasing employment rate of men in the services sector might have contributed to the convergence in the share of part-time work between genders.

\section{Discussion and conclusions}

We analyzed trends in average usual working hours and part-time work in the Nordic countries between 1996 and 2016. We investigated whether there was convergence or divergence in working hours between Denmark, Finland, Norway, and Sweden, between men and women, and between men and women in each country. Moreover, we analyzed whether structural differences and changes in the population have contributed to changes in working hours. Overall, we found that usual working hours were relatively stable in Finland and Sweden, whereas there was a decline in the second half of the 2000s in Denmark. Norway experienced a decline in the first half of the 2000s, but then restored to previous levels. These trends lead to divergence in usual hours between the four countries over time. The gender gap in working hours was evident in all countries: on average, men worked more hours. There was some convergence between men and women, mostly due to a slower decreasing trend for women than for men. We found the clearest trend toward convergence in Sweden, where men's working hours decreased while women's increased.

The trends in average usual working hours largely coincided with opposite trends in part-time work. Denmark experienced a substantial increase in part-time work, while in the other countries, the share of short hours fluctuated around the same level, albeit with some greater variation in Norway. Finland had the lowest levels of part-time work among both men and women. Sweden and Norway had higher levels of part-time work, but with larger gaps between men and women. Denmark became the Nordic champion

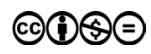


in part-time work in the late 2000s. There was a slight convergence in between men and women, mainly due to men increasingly working part-time. This was most visible in Norway and Sweden, where not only men's part-time work increased but also women's part-time work decreased.

The relative stability in working hours implies no support for universalistic theories of changes toward postindustrial working conditions in the Nordic countries. There were no signs of upward or downward convergence in working hours and part-time work. However, we found some evidence for dualization in working time between higher- and lower educated groups in all countries. The gap in usual hours and part-time work between lower- and middle-educated on the one hand and higher-educated on the other hand was substantial in all countries, in particular among women. It increased or remained stable over time, except for Swedish women. However, our analysis does not show whether working part-time is a symptom of nonstandard and precarious work and lead to financial hardship (Warren 2015b). Marginal part-time work (less than 15 hours) can be associated with greater precariousness and income insecurity in the Nordic context (Rasmussen et al. 2019). However, working in a substantial part-time job does not necessarily need to be a sign of precariousness, especially if a spouse works in a full-time job, and can offer flexibility in balancing work and family (Fagan et al. 2012; Tammelin et al. 2017).

There was some divergence in working hours between countries. Yet, this was mainly due to decreases in average usual working hours and increases in part-time work in Norway and especially Denmark. Examining various sociodemographic groups more closely showed that this decline was driven predominantly by a decrease for the youngest age group. Robustness checks showed that by excluding this group, this declining effect mostly disappeared in these two countries. In Denmark, this decline in working hours might be explained by a large increase in youth unemployment after the economic crisis. Moreover, several policy reforms have been implemented that reinforced this trend. Access to student allowances have been tightened in 2010, possibly resulting in students taking up more part-time jobs (Rasmussen et al. 2019). At the same time, since 2009 , employees with contracts shorter than eight hours per month have been excluded from collective agreements, while in certain sectors, collective agreements allow lower minimum wages for younger age groups. This has made hiring young people and students with short-hour contracts more attractive for employers (Ilsøe et al. 2017). The Danish case illustrates that even though the Nordic countries have a strong tradition of collective bargaining in establishing stability in working conditions and working time (Berg et al. 2014; Gallie 2007), different reform paths are possible and can lead to different working-time outcomes among particular groups.

In Norway, the decline in working hours among the youngest age group was not as steep as in Denmark, but still explains part of the overall decline. In the Norwegian case, however, the effects of the economic crisis were relatively mild and there have been no such distinguishable policy changes toward younger people as in Denmark. It is possible that in Norway, a significant and growing share of younger people stayed in education longer. Moreover, we cannot exclude the option that in Norway a change in the phrasing of the questionnaire or drawing of the survey sample in the years 2003-2004 contributed to the sudden decline in working hours among this group during those years.

An important aspect of intra-regime difference and divergence was gender. Although various regime theories suggest that the Nordic countries are characterized by full-time 
employment and relative gender equity in the labor market (Figart \& Mutari 2000; Rubery et al. 1998), our results showed that part-time work is widespread in the Nordic countries and the gender gap in working hours is considerable. Women are more likely to work part-time than men, especially when they are married, lower-educated, and employed in the services sector. It should be noted, however, that the Nordic gender gap in working hours is relatively small compared to most other European countries (Eurofound 2017) and that it has been decreasing further.

The results showed that there are several structural changes that potentially contributed to the closing of the gender gap. Education levels among women increased considerably during these 20 years. Women's higher education has allowed them to be employed in a greater variety of occupations and advance in their careers (Ellingsæeter 2013), leading to longer working hours. The shift of men from agriculture and manufacturing to service-sector employment coincided with their reduction in working hours and increases in part-time work. Among married women, usual work hours increased and part-time work decreased compared to unmarried women (except in Finland), while among married men no significant changes took place. Although marriage is a somewhat weak proxy for having children, these results suggest that despite the increasing labor market attachment of married women, gender inequality in the household is growing. Our results suggest that married women are working more hours, while married men are not reducing their work hours to take over more tasks at home.

The relatively low levels of R-squared in the models suggest that there is still a substantial amount of unexplained variation in usual working hours and the probability of working part time. Important factors that reinforce differences between countries and genders, but are not directly measurable with labor force survey data, are policy reforms and societal norms. The convergence in working hours between men and women in Norway and Sweden might be due to more gender-oriented policies for work-life balance (Björnberg 2016; Haataja 2009). Differences in norms about having a full-time job might explain why part-time work is still so much more uncommon in Finland than in its neighboring countries. Moreover, norms condition the differences in working-hour patterns between men and women. Nevertheless, norms are not static and can change, bringing along changes in practices. Mósesdóttir and Ellingsæter (2017), for example, have shown how in the case of Norway the norm of women working part-time is under pressure, slowly resulting in changing behaviour.

Another limitation of this research is the lack of comparisons with other countries and regime types. Therefore, it is unclear whether the relative stability that was observed is specific to the Nordic regime. Other studies showed some convergence in Europe in recent years between old and new EU member states and between working-time setting regimes (Eurofound 2016). However, this convergence appears to be mainly due to countries with relatively long usual working hours experiencing a downward trend. Moreover, other dimensions of working-time arrangements must be studied, including the timing of work, the predictability of hours, work-time intensity, and working-time autonomy (Fagan 2001; O'Carroll 2015). Although previous studies indicated that the Nordic countries perform relatively well on these dimensions (Anttila et al. 2015), gender and social inequalities may well be larger and increasing within these arrangements.

EU-LFS data allowed us to analyze trends in working hours and part-time work over time with a large, detailed, and comparative dataset. In addition to showing the differences between countries and genders, this study opens the discussion on intra-regime

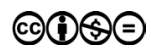


divergence, by examining a group of countries that are often assumed to be very similar. Studying a specific labor market institution, such as working time, allows highlighting the mechanisms behind changes and stability. Regime theories and typologies are useful tools to understand differences and similarities in a complex world but can also obscure slow but important changes that occur within regimes.

\section{References}

Andersen, K., Dølvik, J. E. \& Lyhne Ibsen, C. (2014). Nordic Labour Market Models in Open Markets, Report 132, Brussels: European Trade Union Institute.

Anttila, T., Oinas, T., Tammelin, M. \& Nätti, J. (2015). Working-time regimes and worklife balance in Europe, European Sociological Review 31(6): 713-724. doi: http://doi. org/10.1093/esr/jcv070.

Berg, P., Bosch, G. \& Charest, J. (2014). Working-time configurations: a framework for analyzing diversity across countries, Industrial \& Labor Relations Review 67(3): 805-837. doi: http://doi.org/10.1177/0019793914537452.

Berglund, T. (2014). Crisis and quality of work in the Nordic employment regime, International Review of Sociology 4(2): 259-269. doi: http://doi.org/10.1111/j.1741-3737. 2010.00726.x.

Björnberg, U. (2016). Nordic family policies in a European context, Sociology and Anthropology 4(6): 508-516. doi: http://doi.org/10.13189/sa.2016.040610.

Braverman, H. (1974). Labor and Monopoly of Capital. The Degradation of Work in the Twentieth Century, New York: Monthly Review Press.

Chatzitheochari, S. \& Arber, S. (2012). Class, gender and time poverty: a time use analysis of British workers' free time resources, The British Journal of Sociology 63(3): 451-471. doi: http://doi.org/10.1111/j.1468-4446.2012.01419.x.

Chung, H. (2018). Dualization and the access to occupational family-friendly working-time arrangements across Europe, Social Policy \& Administration 52(2): 491-507. doi: http:// doi.org/10.1111/spol.12379.

Chung, H. \& Tijdens, K. (2013). Working time flexibility components and working time regimes in Europe: Using company-level data across 21 countries, The International Journal of Human Resource Management 24(7): 1418-1434. doi: http://doi.org/10.1080/09 585192.2012.712544.

Ellingsæter, A. L. (2013). Scandinavian welfare states and gender (de)segregation: recent trends and processes, Economic and Industrial Democracy 34(3): 501-518. doi: http:// doi.org/10.1177/0143831X13491616.

Estevez-Abe, M. (2006). Gendering the varieties of capitalism - a study of occupational segregation by sex in advanced industrial societies, World Politics 59(1): 142-175. doi: http://doi.org/10.1353/wp.2007.0016.

Eurofound (2016). Working Time Developments in the $21^{\text {st }}$ Century: Work Duration and its Regulation in the EU, Luxembourg: Publications Office of the European Union.

Eurofound (2017). Working Time Patterns for Sustainable Work, Luxembourg: Publications Office of the European Union.

Fagan, C. (2001). Time, money and the gender order: work orientations and working-time preferences in Britain, Gender, Work \& Organization 8(3): 239-266. doi: http://doi. org/10.1111/1468-0432.00131.

Fagan, C., Lyonette, C., Smith, M. \& Saldaña-Tejeda, A. (2012). The Influence of WorkingTime Arrangements on Work-Life Integration or 'Balance': A Review of the International Evidence, ILO Conditions of Work and Employment Series No. 32, Geneva: International Labour Office. 
Figart, D. M. \& Mutari, E. (2000). Work time regimes in Europe: can flexibility and gender equity coexist?, Journal of Economic Issues 34(4): 847-871. doi: http://doi.org/10.1080/ 00213624.2000 .11506318 .

Furåker, B. (2013). Non-standard employment and perceptions of job characteristics and labour market situation: an intra-Nordic comparison. In M. Koch \& M. Fritz (eds) Non-Standard Employment in Europe. Paradigms, Prevalence and Policy Responses, Basingstoke: Palgrave Macmillan, pp. 150-166.

Gallie, D. (ed.) (2007). Employment Regimes and Quality of Work, Oxford: Oxford University Press.

Gallie, D. \& Russell, H. (2009). Work-family conflict and working conditions in Western Europe, Social Indicators Research 93(3): 469-488. doi: http://doi.org/10.1007/s11205008-9435-0.

Gooderham, P. N., Navrbjerg, S. E., Olsen, K. M. \& Steen, C. R. (2015). The labor market regimes of Denmark and Norway-One Nordic model?, Journal of Industrial Relations 57(2): 166-186. doi: http://doi.org/10.1177/0022185614534103.

Goos, M. \& Manning, A. (2007). Lousy and lovely jobs: the rising polarization of work in Britain, Review of Economics and Statistics 89(1): 118-133. doi: http://doi.org/10.1162/ rest.89.1.118.

Haataja, A. (2009). Fathers' Use of Paternity and Parental Leave in the Nordic Countries, Kela Online Working Papers, 2/2009, Helsinki: Kela.

Hall, P. \& Soskice, D. (2001). Varieties of Capitalism: The Institutional Foundations of Comparative Advantage, Oxford: Oxford University Press.

Hochschild, A. (1997). The time bind, Journal of Labor and Society 1(2): 21-29. doi: http:// doi.org/10.1111/j.1743-4580.1997.tb00019.x.

Ilsøe, A., Larsen, T. P. \& Felbo-Kolding, J. (2017). Living hours under pressure: flexibility loopholes in the Danish I-R model, Employee Relations 39(6): 888-902. doi: http://doi. org/10.1108/ER-03-2017-0049.

Kalleberg, A. (2011). Good Jobs, Bad Jobs: The Rise of Polarized and Precarious Employment Systems in the United States, 1970s to 2000s, New York: Russell Sage Foundation.

Kvist, J., Frizell, J., Hvinden, B. \& Kangas, O. (eds) (2012). Changing Social Inequality: The Nordic Welfare Model in the $21^{\text {st }}$ Century, Bristol: The Policy Press.

Mood, C. (2010). Logistic regression: why we cannot do what we think we can do, and what we can do about it, European Sociological Review, 26(1): 67-82. doi: http://doi. org/10.1093/esr/jcp006.

Mósesdóttir, L. \& Ellingsæter, A. L. (2017). Ideational struggles over women's part-time work in Norway: destabilizing the gender contract, Economic and Industrial Democracy. doi: http://doi.org/10.1177/0143831X16681483.

Mustosmäki, A. (2017). How Bright are the Nordic Lights? Job Quality Trends in Nordic Countries in a Comparative Perspective, Jyväskylä: Jyväskylä Studies in Education, Psychology and Social Research.

Mustosmäki, A., Oinas, T. \& Anttila, T. (2017). Abating inequalities? Job quality at the intersection of class and gender in Finland 1977-2013, Acta Sociologica 60(3): 228-245. doi: http://doi.org/10.1177/0001699316657580.

OECD (2018). Is the Last Mile the Longest? Economic Gains from Gender Equality in Nordic Countries, Paris: OECD Publishing. doi: http://doi.org/10.1787/9789264300040-en.

O'Carroll, A. (2015). Working Time, Knowledge Work and Post-Industrial Society: Unpredictable Work, London: Palgrave Macmillan.

Rasmussen, S., Nätti, J., Larsen, T. P., Ilsøe, A. \& Harde, A. H. (2019). Non-standard employment in the Nordics - towards precarious work?, Nordic Journal of Working Life Studies 9(S6): 7-32. doi: http://doi.org/10.18291/njwls.v9iS6.114689. 
Rubery, J., Smith, M. \& Fagan, C. (1998). National working-time regimes and equal opportunities, Feminist Economics 4(1): 71-101. doi: http://doi.org/10.1080/135457098338572.

Sterud, T., Tynes, T., Sivesind Mehlum, I., Veiersted, K. B., Bergbom, B., Airila, A., Johansson, B., Brendler-Lindqvist, M., Hviid, K. \& Flyvholm, M.-A. (2018). A systematic review of working conditions and occupational health among immigrants in Europe and Canada, BMC Public Health 18: 770. doi: http://doi.org/10.1186/s12889-018-5703-3.

Tammelin, M., Malinen, K., Verhoef, M. \& Rönkä,A. (2017). Work schedules and work-family conflict among dual earners in Finland, the Netherlands and the United Kingdom, Journal of Family Issues 38(1): 3-24. doi: http://doi.org/10.1177/0192513X15585810.

Warren, T. (2015a). Work-life balance/imbalance: the dominance of the middle class and the neglect of the working class, The British Journal of Sociology 66(4): 691-717. doi: http:// doi.org/10.1111/1468-4446.12160.

Warren, T. (2015b). Work-time underemployment and financial hardship: class inequalities and recession in the UK, Work, Employment and Society 29(2): 191-212. doi: http://doi. org/10.1177/0950017014559264. 


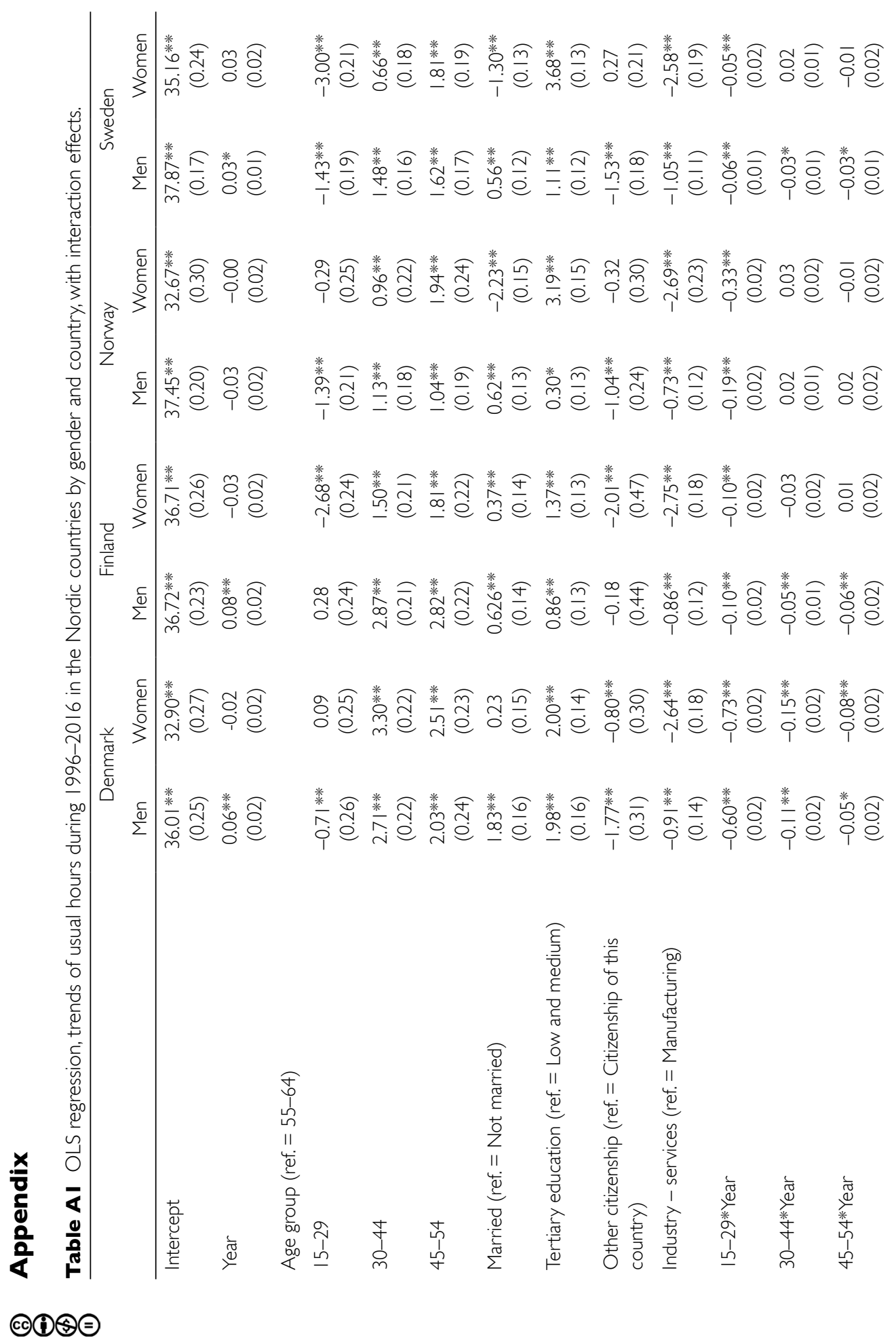




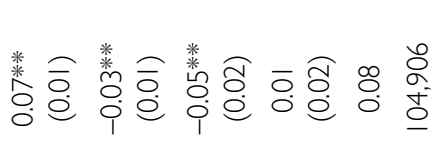

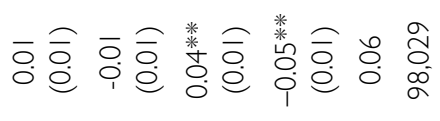

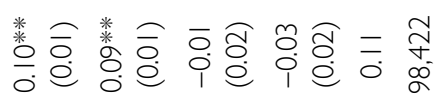

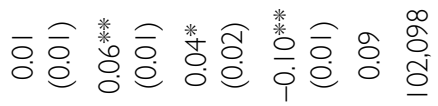

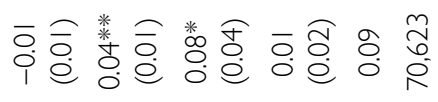

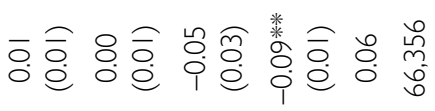

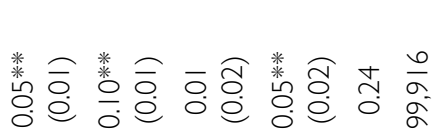

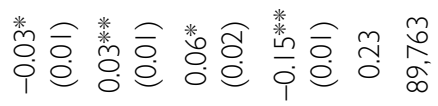

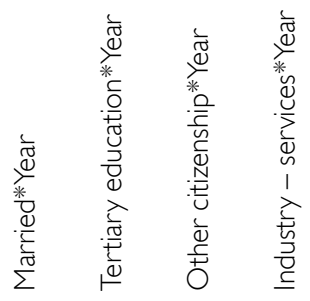

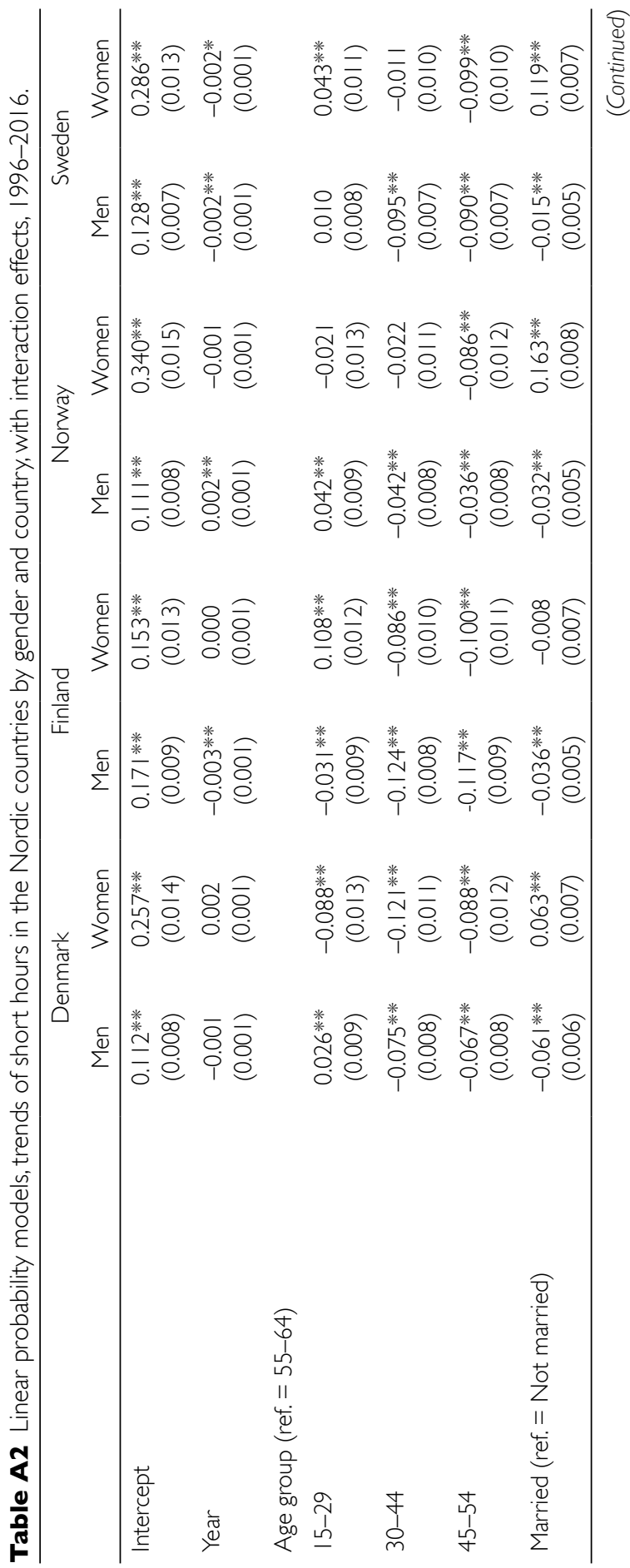

(ㄷ)(1)(우 


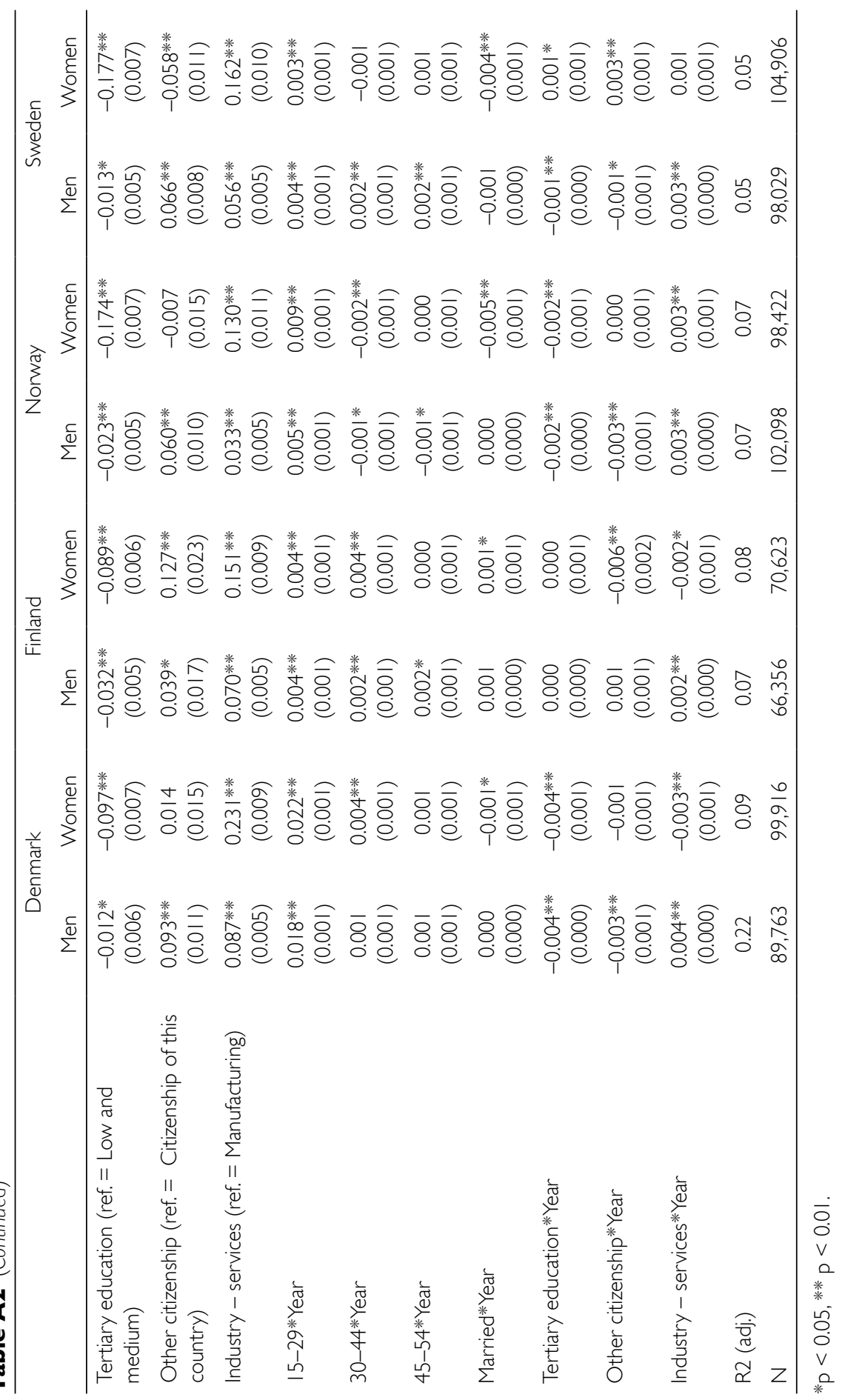

